\title{
CARBOHYDRATE ACCUMULATION IN DEVELOPING GRAINS OF WHEAT GENOTYPES
}

\author{
GUTAM SRIDHAR*, VIRENDRA NATH, G.C. SRIVASTAVA, AND SANTOSH KUMARI \\ Division of Plant Physiology, Indian Agricultural Research Institute, New Delhi 110012 \\ Received on 31 Dec., 2003, Revised on 7 May, 2005
}

\begin{abstract}
An experiment was conducted to estimate the total sugars and starch contents in three tetraploid and three hexaploid wheat genotypes at different days after anthesis (DAA). The sugar content decreased continuously from 5 DAA till harvest whereas the starch content increased at the same time. The new plant type, DL 1226-2, recorded highest amount of sugars at 15 DAA and starch at harvest stage.
\end{abstract}

Key words: Developing grains, starch, sugars, wheat

The wheat genotypes differ in the starch and sugar content in the developing grains (Kumar and Singh 1981). The new plant types developed at Indian Agricultural Research Institute (IARI) have heavier grains. To understand the pattern of carbohydrate accumulation in the developing seeds of new plant type in comparison to other genotypes, total sugars and starch contents were determined.

Three genotypes each of hexaploid (DL 1266-1, DL 1266-2 and PBW 343) and tetraploid (HD 4530, HI 8498, and PDW 233) were taken for study. Among hexaploid lines, former two were new plant type. Total soluble sugars in seeds were estimated colorimetrically (Dubois et al. 1951). The starch content was estimated in dry residue left after sugar extraction by phenol sulphuric acid method (Colowick and Kaplan 1957). The starch content was calculated by multiplying glucose values by 0.9 . The experimental data was subjected to statistical analysis following completely randomized design as described by Panse and Sukhatme (1961). Duncan's Multiple Range Test (DMRT) was carried out using MSTAT-C (version 2.10) to know the significant difference among the genotypes.
Total sugars content varied significantly among the genotypes at all the stages (Table 1). It was further observed that the total sugar content was significantly higher in the hexaploid genotypes compared to tetraploids at all the stages. Total sugars decreased continuously from 15 DAA until harvest in all the genotypes. At 15 DAA, the genotype DL 1266-2 followed by DL-1266-1 recorded significantly higher total sugars content over all other genotypes while the rest of the genotypes were at par with each other at this stage. At 25 DAA, the hexaploid genotype DL-1266-2 recorded higher total sugars content ( $91.84 \mathrm{mg} / \mathrm{g}$ dry wt.) compared to all other genotypes, irrespective of hexaploid or tetraploid. Other two hexaploid genotypes, i.e. DL 1266-1 and PBW-343 were at par with each other where no significant differences were observed among tetraploids at this stage. At 35 DAA, the hexaploid genotype DL-1266-2 recorded significantly higher total sugars content than all other genotypes. The genotypes DL-1266-1 and PBW343 of hexaploids and PDW-233, HD-4530 and HI-8498 of tetraploids did not show any significant differences among themselves both at 25 and 35 DAA. A similar trend continued at harvest with DL-1266-2 having higher total sugar content than all other genotypes. The data on

\footnotetext{
* Corresponding author's present address: Scientist, National Research Centre for Medicinal and Aromatic Plants, Boriavi, Anand 387 310, Gujarat. E-mail: gutam2000@yahoo.com
} 
Table 1. Genotypic differences among hexaploid and tetraploid wheats in starch content (mg/g dry wt) in the developing grains.

\begin{tabular}{|c|c|c|c|c|}
\hline \multirow[t]{2}{*}{ Genotypes } & \multicolumn{4}{|c|}{ Days after anthesis } \\
\hline & 15 & 25 & 35 & Harvest \\
\hline \multicolumn{5}{|l|}{ Hexaploid } \\
\hline DL 1266-1 & $315.00 \mathrm{ab}^{*}$ & $528.00 \mathrm{ab}$ & $677.00 \mathrm{ab}$ & $700.00 \mathrm{ab}$ \\
\hline DL 1266-2 & $342.00 \mathrm{a}$ & $564.00 \mathrm{a}$ & 699.00 a & 710.00 a \\
\hline PBW 343 & $278.00 \mathrm{bc}$ & $506.00 \mathrm{abc}$ & $644.00 \mathrm{bc}$ & $655.00 \mathrm{bc}$ \\
\hline Sub Mean & 311.67 & 532.67 & 673.16 & 688.33 \\
\hline \multicolumn{5}{|l|}{ Tetraploid } \\
\hline PDW 233 & $222.00 \mathrm{~d}$ & $437.00 \mathrm{~d}$ & $629.00 \mathrm{c}$ & $635.00 \mathrm{c}$ \\
\hline HD 4530 & $256.00 \mathrm{~cd}$ & $472.00 \mathrm{bcd}$ & $618.00 \mathrm{c}$ & $624.00 \mathrm{c}$ \\
\hline HI 8498 & $244.00 \mathrm{~cd}$ & $456.00 \mathrm{~cd}$ & $606.00 \mathrm{c}$ & $614.00 \mathrm{c}$ \\
\hline Sub mean & 240.67 & 455.00 & 617.80 & 624.78 \\
\hline Total mean & 276.17 & 493.83 & 645.48 & 656.33 \\
\hline
\end{tabular}

* Duncan’s Multiple Range Test. In a column, means followed by a common letter are not significantly different at $5 \%$ level.

starch content presented in Table 2 indicated significant differences among the genotypes at all the stages. The starch content increased continuously from 15 DAA until harvest in all the genotypes. Among the genotypes, the starch content was higher in hexaploids compared to tetraploids at all the stages. At 15 DAA, the genotype DL-1266-2 followed by DL-1266-1 recorded significantly higher starch content over all other genotypes, irrespective of hexaploids or tetraploids. The starch content was found maximum (342 mg/g dry wt.) in DL1266-2 of hexaploids. No significant differences were observed between the genotypes among hexaploids and tetraploids at 25 DAA. However, maximum starch content was recorded in DL-1266-2 of hexaploids and minimum in PDW-233 of tetraploids. At 35 DAA, both DL 1266-1 and DL 1266-2 continued to maintain higher starch content. None of the genotypes among tetraploids differed significantly in starch content at this stage. At harvest also, the same trend was observed in all the genotypes tested. However, the maximum starch content (710 mg/g dry wt.) was recorded in DL-1266-2 of hexaploids and the minimum (614 mg/g dry wt.) in HI8498 of tetraploids.

In conclusion, results revealed significant differences in the total sugars content in the seeds among genotypes, which gradually decreased from 15 DAA until harvest. Among the genotypes, hexaploids showed higher sugars content than tetraploids at all the stages. Similar results were observed by several authors (Kumar and Singh 1981, Singhal et al. 1989, Sekhon and Singh 1994). The sugars content of the grains was greater at anthesis and then decreased during grain filling from 15 DAA onwards which showed concurrence with Mi et al. (2002). The starch content of seeds increased from 15 DAA till harvest in all the genotypes. Among the genotypes, hexaploids (new plant types) had significantly higher starch content compared to tetraploids. The slow starch 


\section{CARBOHYDRATE ACCUMULATION IN WHEAT GRAINS}

Table 2. Genotypic differences among hexaploid and tetraploid wheats in total sugar content (mg/g dry wt.) in the developing grains.

\begin{tabular}{lcccc}
\hline Genotypes & \multicolumn{3}{c}{ Days after anthesis } & Harvest \\
\cline { 2 - 4 } & $\mathbf{1 5}$ & $\mathbf{2 5}$ & $\mathbf{3 5}$ & \\
\hline Hexaploid & & & $32.46 \mathrm{c}$ \\
DL 1266-1 & $171.74 \mathrm{ab}^{*}$ & $80.72 \mathrm{~b}$ & $46.10 \mathrm{~b}$ & $49.69 \mathrm{a}$ \\
DL 1266-2 & $229.62 \mathrm{a}$ & $91.84 \mathrm{a}$ & $58.57 \mathrm{a}$ & $38.63 \mathrm{~b}$ \\
PBW 343 & $135.48 \mathrm{bc}$ & $76.76 \mathrm{~b}$ & $42.16 \mathrm{~b}$ & 40.26 \\
Sub Mean & 178.95 & 83.11 & 48.94 & $29.93 \mathrm{c}$ \\
Tetraploid & & & $31.10 \mathrm{c}$ & $26.78 \mathrm{c}$ \\
PDW 233 & $106.41 \mathrm{c}$ & $54.91 \mathrm{c}$ & $30.14 \mathrm{c}$ & $28.87 \mathrm{c}$ \\
HD 4530 & $124.82 \mathrm{bc}$ & $60.95 \mathrm{c}$ & $33.50 \mathrm{c}$ & 28.52 \\
HI 8498 & $119.34 \mathrm{bc}$ & $61.45 \mathrm{c}$ & 31.58 & 34.39 \\
Sub mean & 116.86 & 59.10 & 40.26 & \\
Total mean & 147.90 & 71.11 & & \\
\hline
\end{tabular}

* Duncan’s Multiple Range Test. In a column, means followed by a common letter are not significantly different at 5\% level.

synthesis in the grains of tetraploids might be one of the reasons for slow grain filling. The tetraploids might have more endogenous cells, hence, cell division might have taken longer time than in hexaploids and starch accumulation delayed (Mi et al. 2002). A delayed starch synthesis resulted in weak sink strength at early stages (Jenner et al. 1991) and might have induced a negative feed back on carbohydrate mobilisation from stem and leaf sheath to the grains (Wardlaw 1990).

\section{REFERENCES}

Colowick, S.P. and Kaplan, N.O. (1957). Methods in Enzymology, pp 30. Academic Press, N. Y.

Dubois, M., Giles, K.A., Humilton, J.K., Rebers, P.A. and Simth, F. (1951). A colorimetric method for determination of sugars. Nature (London) 168: 167.

Jenner, C.F. (1991). Effect of exposure of wheat ears to high temperature on dry matter accumulation and carbohydrate metabolism in grain of two cultivars. Aust. J. Plant Physiol. 18: 165-177.
Kumar, R and Singh, R. (1981). Free sugars and their relationship with grain size and starch content in developing wheat grains. J. Sci. Food and Agri. 32: 229234.

Mi, G., Li, T., Zhang, F. and Zhang, J. (2002). Carbohydrate storage and utilization during grain filling as regulated by nitrogen application in two wheat cultivars. J. Plant Nutr. 25: 213-229.

Panse, V.G. and Sukhatme, P.V. (1961). Statistical Methods for Agricultural Workers. ICAR, New Delhi.

Sekhon N.K. and Singh G. (1994). Effect of growth regulators and date of sowing on grain development in wheat. Indian J. Plant Physiol. 37: 1-4.

Singhal, N.C., Srivastava, K.N. and Mehta, S.L. (1989). Pattern of dry matter and protein accumulation in developing wheat seeds and their relationship. Indian J. Genet. and Plant Breed. 49: 95-102.

Wardlaw, I.F. (1990). The control of carbon partitioning in plants. New Phytol. 116: 341-381. 